\title{
Assessment of Maxillo-Mandibular Implant Sites by Digitized Volumetric Tomography
}

\author{
Dubey $\mathrm{A}^{1}$, Dangorekhasbage $\mathrm{S}^{2}$, Bhowate $\mathrm{R}^{3}$ \\ ${ }^{1}$ Department of Oral Medicine and Radiology, Sharad Pawar Dental College, Rungta College of Dental Sciences and \\ Research, Bhilai, India. 'Department of Oral Medicine and Radiology, Sharad Pawar Dental College, Datta Meghe \\ Institute of Medical Sciences, Wardha, Maharashtra, India. ${ }^{3}$ Department of Oral Medicine and Radiology, Sharad Pawar \\ Dental College, Datta Meghe Institute of Medical Sciences, Wardha, Maharashtra, India.
}

\section{ABSTRACT}

\section{BACKGROUND}

Radiographic examination plays a vital role in pre-evaluation of implant site for assessing the amount of bone available and to assess the proximity of implant site to vital anatomical structures. We wanted to assess maxillo-mandibular implant sites by Digitized Volumetric Tomography.

\section{METHODS}

This cross-sectional study included 36 implant sites in 25 healthy subjects. All the sites were evaluated by measuring the height and width of the available alveolar ridge, the proximity to maxillary sinus as well as inferior alveolar canal, the width of the cortical plates and by evaluating visibility of mandibular canal by using Digitized Volumetric Tomography.

\section{RESULTS}

$23(63.88 \%)$ were maxillary implant sites and 13 (36.11\%) were mandibular sites. The presence of type A bone was found to be maximum at implant sites. Out of 20 maxillary posterior implant sites, $2(10 \%)$ sites belonged to SA1 group, 7 (35\%) sites to SA2 group, 8 sites to SA3 group and 3 sites to SA4 group. At 8 sites, mandibular canal was clearly visible. Significant difference is observed between buccal cortical width of maxilla and mandible $(p<0.05)$.

\section{CONCLUSIONS}

Digitized Volumetric Tomography successfully showed the presence and proximity of vital surrounding structures and anatomical variations. This can be used in assessment of implant site and thus helps in successful implant placement with excellent prognosis.

\section{KEY WORDS}

Implant, Digitized Volumetric Tomography (DVT), Maxillary, Mandibular
Corresponding Author: Dr. Dangorekhasbage $S$, Department of Oral Medicine \& Radiology, Sharad Pawar Dental College, Sawangi (M), Wardha, Maharashtra, India.

E-mail: dangore_suwarna@rediffmail.com

DOI: $10.14260 /$ jemds/2019/819

Financial or Other Competing Interests: None.

How to Cite This Article:

Dubey A, Dangorekhasbage S, Bhowate R. Assessment of maxillo-mandibular implant sites by digitized volumetric tomography. J. Evolution Med. Dent. Sci. 2019;8(50): 3780-3784 DOI: 


\section{BACKGROUND}

The modern era of dental implantology was ushered in by the pioneering work of Branemark and his co-workers. Their research demonstrated the relationship between bone and implant that now is known as osseointegeration. [1] Since then the use of implant has gained immense popularity and wide acceptance. Nevertheless, implant prosthesis offers a more predictable treatment outcome than traditional restoration, though the result varies region wise. The longitudinal clinical studies have reported success rate of 10 years ranging from $81 \%$ to $85 \%$ for the maxilla and from $98 \%$ to $99 \%$ for the anterior mandible. [2] On the contrary, highest failure rate has been reported for the posterior maxilla which pertains to poor bone quality in conjunction with inadequate bone volume, related to both the size of the maxillary sinus and resorption of the alveolar ridge. Similarly, the preoperative assessment of dental implant site in the posterior segment of the mandible requires accurate localization of the mandibular canal. [3]Actually a number of advanced imaging techniques are used to evaluate anatomy of various oral maxillofacial structures including Digital volume tomography (DVT).[4,5,6]

Digital volume tomography (DVT) is a potentially efficient technique for visualizing the bony structures in the head and neck. Digital volume tomography (DVT) uses a threedimensional, cone-shaped ray beam and a two-dimensional flat-panel detector. Due to this technology, a single rotation around the patient is sufficient to scan a three-dimensional volume with lower radiation exposure.[7] As conventional radiographs don't provide the precise determination of quantity and quality of the available bone which is critical for the long term success of implants, the present study was undertaken to assess maxillo-mandibular implant sites by using DVT.

\section{METHODS}

This Institutional Ethical Committee approved cross-sectional study comprised of 25 subjects having one or more missing teeth. Convenient sample size was used based on parent article. The inclusion criteria were the subjects in age group between 15 to 70 years, having one or more edentulous areas in the jaw with adequate alveolar ridge height. Patients suffering from any systemic disease which may affect the bone integrity like immune-compromised patients, patients suffering from bleeding disorders, diabetes mellitus, psychological and mental disorders, patients with habit of bruxism, patients undergoing radiotherapy, patients on bisphosphonates were not included in the study. After informing about the step by step procedure and potential risk factors of radiation exposure to the patient in the language of his/her understanding, consent was taken for undergoing clinical and radiographic, DVT examination. Then thorough case history, oral examination was carried out which was then followed by DVT examination.

Phillips AlluraXper FD20 3D RA, Digital Subtraction Angiography unit (Netherlands) was used for DVT images. Three dimensional (3D) images, as well as multiplanar reconstruction (MPR) images were obtained using Expert 3D
CT software at computer workstation. The coronal cut sections were taken for the measurement of the height, width at implant sites as well as to assess the proximity to the adjacent vital structures.

Following variables were evaluated

1. Measurement of the height and width of the available alveolar ridge.

2. Proximity to maxillary sinus.

3. Proximity to inferior alveolar canal.

4. Visibility of mandibular canal.

5. Width of the cortical plates.

Measurement of the height and width of the available alveolar ridge was done using Exper 3D CT software in DVT at computer workstation. For mandibular anterior region, the height of the ridge was calculated from crest of ridge to inferior border of mandible. For mandibular posterior region, the height of ridge was calculated from the crest of ridge to superior border of inferior alveolar canal, buccolingual width of the ridge was calculated from the inner buccal and inner lingual cortical plates in DVT. Coronal view of DVT scan showing measurement of bone height and width along with thickness of cortical plates of mandibular implant site. For maxillary anterior region, the height of the alveolar ridge was calculated from the crest of the ridge to the inferior border of nasal fossa. For maxillary posterior region, the height of the ridge was calculated from the superior border of crest of ridge to the inferior border of maxillary sinus. Coronal view of DVT scan showing measurement of bone height and width of maxillary implant site. Proximity to maxillary sinus at the proposed implant site was measured according to criteria given by Misch.[8] Similar criteria as above were used to evaluate the proximity to the inferior alveolar canal and the visibility of mandibular canal at the implant site was interpreted and graded into three groups.

0- Mandibular canal could not be identified

1- Mandibular canal was visible but had diffuse borders

2- Mandibular canal was clearly visible

Clearly visible mandibular canal is shown in coronal view of DVT scan. Depending upon the available height and width at the proposed implant site, availability of bone was divided into four categories A, B, C and D according to criteria given by Manuel Chanavaz, a French professor who presented volumetric bone classification at Paris in 1986.[9]

\section{Statistical Analysis}

Data analysis was done by using Statistical Package for the Social Sciences (SPSS) Software version 16. Data was analysed using paired and unpaired Students t-test. The pvalue $\mathrm{p}<0.0$ was considered statistically significant.

\section{RESULTS}

The present prospective study consisted of 36 implant sites in 25 patients with mean age $32.60 \pm 10.60$ years. Out of total 25 patients, $15(60 \%)$ were male and $10(40 \%)$ were female. However, out of total 36 implant sites, 21 (58.33\%) were in male and 15 (41.66\%) were in female. 


\section{Available Bone Type at Implant Sites}

Out of the 36 implant sites, 23 (63.88\%) were maxillary implant sites and 13 (36.11\%) were mandibular sites. Amongst 23 maxillary implant sites, only $3(13 \%)$ were of the anterior region, whereas there was no anterior implant site in mandible. In maxillary arch, as per Manuel Chanavaz's French volumetric classification, $11(47.83 \%)$ implant sites had A type of bone, $8(34.78 \%)$ showed B type of bone and 1 implant site $(4.35 \%)$ had $C$ type of bone while in maxillary anterior region 2 implant sites (8.7\%) had type A bone and 1 (4.35\%) had type B bone. Amongst mandibular implant sites, 12 implant sites (92.31\%) had type A bone, and only 1 $(2.78 \%)$ had type B bone. No implant site had type D bone. Type A bone was found in maxillary and mandibular posterior implant sites. By applying the Chi-square test statistically significant difference ( $p$ value $<0.05$ ) was found between implant sites of maxilla and mandible in the posterior region as shown in Table 1 . Type A and C type of bone was maximum in male implant sites while type $B$ bone was higher in female. Statistically significant difference found between type of implant sites in males and females. ( $p$ value $<0.05$ ). Concerning relationship between type of bone and age of the patients, the age group 21-30 years showed the highest prevalence of type A bone being a younger age group, followed by age group 31-40 years. Type B bone was also prevalent in younger age group of 21-30 years. While, type $\mathrm{C}$ bone was seen in one male patient aged between $61-70$ years.

\section{Proximity of Maxillary Posterior Implant Sites to the Maxillary Sinus}

Out of 20 maxillary posterior implant sites, 2 (10\%) sites belonged to Subantral (SA) SA1 group, 7 (35\%) sites belonged to SA2 group. (Table 2)In SA1 sites, conventional implant procedure was recommended as the height was greater than $12 \mathrm{~mm}$ whereas in SA2 group where the height was between 10-12 $\mathrm{mm}$ from the floor of the maxillary sinus, sinus lift procedure was recommended. In SA3 and SA4 groups, in which the height is $5-10 \mathrm{~mm}$ and less than $5 \mathrm{~mm}$ respectively, lateral wall approach sinus graft and delayed Div A root form is a choice of implant placement procedure.

\section{Proximity of Mandibular Posterior Implant Sites to the Inferior Alveolar Canal}

Out of 13 mandibular implant sites. 9 implant sites (69.23\%) had height beyond $12 \mathrm{~mm}$ from the superior border of the canal while no implant site height was less than $5 \mathrm{~mm}$ from the canal as shown in table 3. With reference to ease of visibility of mandibular canal, canal was not visible at 2 sites (15.38\%). The canal was diffusely visible in 3 (20.07\%) implant sites. In 8 implant sites (61.53\%), the canal was clearly visible.

\section{Presence of Bony Concavities at Implant Sites}

Out of 33 posterior implant sites, bony concavities were present in 5 implant sites (15.15\%). Four (30.77\%) were mandibular implant sites and only $1(5 \%)$ was maxillary implant site.

\section{Distribution of Cortical Bone Width in Maxilla and Mandible}

The total buccal cortical width in maxilla was 26.73 while the total buccal cortical width in mandible was 21.69. Using the Unpaired Student t- test statistically significant difference was found between the buccal cortical width of maxilla and mandible $(\mathrm{p}<0.05)$. Similar statistically significant difference was found between the lingual/palatal cortical width of maxilla and mandible with $\mathrm{p}<0.05$ and $\mathrm{t}$ value 2.83 as shown in Table 4.

\begin{tabular}{|c|c|c|c|c|c|c|c|c|c|}
\hline \multirow{2}{*}{\begin{tabular}{|c|} 
Implant \\
Sites \\
\end{tabular}} & \multicolumn{4}{|c|}{ Anterior } & \multicolumn{4}{|c|}{ Posterior } & \multirow{2}{*}{$\begin{array}{c}\text { Total } \\
\text { No } \\
(\%)\end{array}$} \\
\hline & $\begin{array}{c}\text { A } \\
\text { No } \\
(\%)\end{array}$ & $\begin{array}{c}\text { B } \\
\text { No } \\
(\%)\end{array}$ & $\begin{array}{c}\text { C } \\
\text { No } \\
(\%)\end{array}$ & $\begin{array}{c}D \\
\text { No } \\
(\%)\end{array}$ & $\begin{array}{c}\text { A } \\
\text { No } \\
(\%)\end{array}$ & $\begin{array}{c}\text { B } \\
\text { No } \\
(\%)\end{array}$ & $\begin{array}{c}\mathrm{C} \\
\text { No } \\
(\%)\end{array}$ & $\begin{array}{c}\text { D } \\
\text { No } \\
(\%)\end{array}$ & \\
\hline Maxillary & $\begin{array}{c}2 \\
(8.70)\end{array}$ & $\begin{array}{c}1 \\
(4.35)\end{array}$ & $\begin{array}{c}0 \\
(0)\end{array}$ & $\begin{array}{c}0 \\
(0)\end{array}$ & $\begin{array}{c}11 \\
(47.83)\end{array}$ & $\begin{array}{c}8 \\
(34.78)\end{array}$ & $\begin{array}{c}1 \\
(4.35)\end{array}$ & $\begin{array}{c}0 \\
0 \\
(0)\end{array}$ & $\begin{array}{c}23 \\
(63.89)\end{array}$ \\
\hline Mandibular & $\begin{array}{c}0 \\
(0 \%)\end{array}$ & $\begin{array}{c}0 \\
(0 \%)\end{array}$ & $\begin{array}{c}0 \\
(0 \%)\end{array}$ & $\begin{array}{c}0 \\
(0 \%)\end{array}$ & $\begin{array}{c}12 \\
(92.31 \%)\end{array}$ & $\begin{array}{c}1 \\
(7.69 \%)\end{array}$ & $\begin{array}{c}0 \\
(0 \%)\end{array}$ & $\begin{array}{c}0 \\
(0 \%)\end{array}$ & $\begin{array}{c}13 \\
(36.11)\end{array}$ \\
\hline $\begin{array}{c}\text { Total } \\
(\mathrm{n}=36)\end{array}$ & $\begin{array}{c}2 \\
(5.56 \%\end{array}$ & $\begin{array}{c}1 \\
(2.78 \%)\end{array}$ & $\begin{array}{c}0 \\
(0 \%)\end{array}$ & $\begin{array}{c}0 \\
(0 \%)\end{array}$ & $\begin{array}{c}23 \\
(63.89 \%)\end{array}$ & $\begin{array}{c}9 \\
(25 \%)\end{array}$ & $\begin{array}{c}1 \\
(2.78 \%)\end{array}$ & $\begin{array}{c}0 \\
(0 \%)\end{array}$ & $\begin{array}{c}36 \\
(100)\end{array}$ \\
\hline «2-value & & - & & & & 7.31 & & & \\
\hline$p$-value & & - & & & & $0.025, \mathrm{~S}, \mathrm{p}$ & $p<0.05$ & & \\
\hline
\end{tabular}

Table 1. Relationship between Available Bone at Implant Sites and Anterior/Posterior Region of Jaw (Based on Manuel Chanavaz's French Volumetric Classification)

\begin{tabular}{|c|c|c|c|c|}
\hline Implant Sites & SA1 & SA2 & SA3 & SA4 \\
\hline Height available at the implant site $(\mathrm{mm})$ & $>12$ & $10-12$ & $5-10$ & $<5$ \\
\hline Total (n=20) & $2(10 \%)$ & $\mathbf{7 ( 3 5 \% )}$ & $\mathbf{8 ( 4 0 \% )}$ & $\mathbf{3 ( 1 5 \% )}$ \\
\hline Table 2. Proximity of Maxillary Posterior Implant Sites \\
to the Maxillary Sinus \\
\hline
\end{tabular}

\begin{tabular}{|c|c|c|c|c|}
\hline Implant sites & $>12 \mathbf{~ m m}$ & $\mathbf{1 0 - 1 2} \mathbf{~ m m}$ & $\mathbf{5 - 1 0} \mathbf{~ m m}$ & $<\mathbf{5 m m}$ \\
\hline Total $(\mathrm{n}=13)$ & $9(69.23 \%)$ & $2(15.38 \%)$ & $1(7.69 \%)$ & $0(0 \%)$ \\
\hline \multicolumn{3}{|c|}{ Table 3. Proximity of Mandibular Posterior Implant Sites to the } \\
Inferior Alveolar Canal \\
\hline
\end{tabular}

\begin{tabular}{|c|c|c|c|c|c|c|c|c|}
\hline & 忢 & $\sum_{\Sigma}^{\varpi}$ & ڤे & 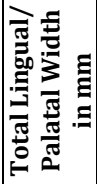 & $\sum^{\Xi}$ & के & 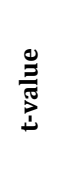 & 冚 \\
\hline $\begin{array}{l}\text { Width of cortical } \\
\text { plate in maxilla } \\
(n=13)\end{array}$ & 26.73 & 1.16 & 0.37 & 26.85 & 1.16 & 0.44 & 0.04 & $\begin{array}{c}0.96 \\
\text { NS, } p>0.05\end{array}$ \\
\hline $\begin{array}{l}\text { Width of cortical } \\
\text { plate in mandible } \\
(\mathrm{n}=20)\end{array}$ & 21.69 & 1.66 & 0.64 & 20.65 & 1.58 & 0.40 & 0.37 & $\begin{array}{c}0.70 \mathrm{NS} \\
p>0.05\end{array}$ \\
\hline t-value & \multicolumn{3}{|c|}{2.97} & \multicolumn{3}{|c|}{2.83} & & \\
\hline p-value & \multicolumn{3}{|c|}{$0.005, \mathrm{~S}, \mathrm{p}<0.05$} & \multicolumn{3}{|c|}{$0.008, \mathrm{~S}, \mathrm{p}<0.05$} & & \\
\hline \multicolumn{9}{|c|}{ Table 4. Distribution of Cortical Bone Width in Maxilla and Mandible } \\
\hline \multicolumn{9}{|c|}{ (S - significant, NS - not significant) } \\
\hline
\end{tabular}

\section{DISCUSSION}

Now days the rehabilitation of partial or complete edentulism using osseointegrated implants is a method of choice. But, one of the common difficulties in implant dentistry is bone atrophy after tooth loss, which in some cases, prevents immediate implant placement or requires additional surgical intervention to re-establish bone volume. To visualize these bony changes, appropriate radiographic examination is mandatory prior to every implant surgery.[10,11]

In this study assessment of implant site by DVT depicted presence of Type A bone at maximum implant sites (69.44\%). 
With reference to age group of patients, the highest prevalence of type A bone was noted in 21 to 40 years. These patients were advised immediate implant placement considering the favourable factors at the implant site. However, $22 \%$ of implant sites in the same age group showed Type B bone. This may be due to delay in replacing the teeth following its loss. Hence, resorption might have taken place in that interim period. Similarly, in a study by Jaju PP et al[12] who studied 61 implant sites in 25 patients, type B bone (63.93\%) was more prevalent. While, type $\mathrm{C}$ bone was seen in 1 male patient aged between 61-70 years attributing to his old age and alveolar ridge resorption and reiterating the fact that prolonged loss of teeth without replacement cause disuse atrophy of alveolar bone.[13] It is stated that the ageassociated bone loss is about $1 \%$ in women and $0.5 \%$ in males annually. Women represent a greater percentage of patients with residual ridge resorption than men.[13] Shilpa BS et al[14] reported that the use of short implants under strict clinical protocol can be a safe minimally invasive technique with minimal bone resorption and $100 \%$ survival at 1 -year follow-up.

This study reiterates the point that cross-sectional reformations provide the best assessment of the shape and contour of the ridges as believed by Stephen L. G. et al[15] Similarly, Melvyn S S et al.[16] found Dentascan images more accurately reflected the true osseous topography and considered it as a valuable diagnostic aid.

DVT offers the option of skull imaging with high geometric accuracy in all spatial planes as well as threedimensional reconstruction at high resolution. Up to now; these options have only been available with standard CT.[13] DVT provides information regarding the cortical bone in the floor of the nasal cavity and maxillary sinuses prior to implant placement.

According to the height criteria given by Misch, four groups were formed and subsequently the implant sites were advised SA treatment option. Out of 20 maxillary posterior implant sites, 2 implant sites belonged to Subantral (SA) SA1 group where the available height at implant site was $>12 \mathrm{~mm}$. Here, a conventional implant procedure was recommended. Seven maxillary posterior sites belonged to SA2 group (35\%) where available height at implant site was $10-12 \mathrm{~mm}$ from alveolar crest to the floor of the maxillary sinus. Div A form sinus lift procedure was advised to these patients. A Lateral wall approach sinus graft and delayed Div A root form implant procedure was advised in SA3 and SA 4 cases. Hence, it can be concluded that the implant sites belonging to group $\mathrm{C}$ needed ridge augmentation and/or osteoplasty procedure. In this study, no patients had type D bone. On the contrary, with reference to the same criteria, available ridge height was found to be greater ( $>12 \mathrm{~mm}$ ) at most of the implant sites in the study by Jaju P P et al[12] (10 out of 12). Thus conventional implant procedure was recommended by them in maximum sites.

Proximity of mandibular posterior implant sites to the inferior alveolar canal was assessed using coronal cuts in DVT and findings were comparable to the study by Lindh and Petersson et al.[17] With reference to ease of visibility of mandibular canal, canal was clearly visible in 8 implant sites (61.53\%), diffusely visible in $3(20.07 \%)$ implant sites and not visible at 2 sites (15.38\%) findings are comparable to the study by Chakraborty R. et al.[18]
Presence of bony concavities alters the path way of implant placement. Its presence warns the surgeon to alter the orientation of implant to avoid cortical plate perforation and be ready with augmentation procedures.[19] The present study also depicted presence of 5 concavities (4 mandibular and 1 maxilla), findings are similar to the study by Jaju PP et al,[12] who stated that concavities are observed to be more in the mandible.

With reference to cortical width measurement in maxilla and mandible, a minimum of $1 \mathrm{~mm}$ of cortical bone was shown to be necessary for increasing success rates. The findings of present study showed that almost all implant sites had adequate bone thickness for implant placement. In the present study, the gender wise distribution of total mean cortical width on buccal and lingual side showed that the cortical width on both sides was slightly more amongst males. Reason for this could be men have stronger masticatory forces than women.[20]On the other hand, although buccal cortical bone thickness increases gradually posteriorly in women, it is thinner than the lingual cortical bone thickness because the masticatory forces of women tend to be weaker than that of men.[12] In the present study, the mandibular buccal cortical bone thickness was slightly more in posterior regions than the lingual cortical bone thickness which decreased from the anterior to posterior regions. This was related to bucco-lingual molar inclination.[19] Overall findings relevant to cortical width measurement revealed that DVT is useful in measurement of cortical bone thickness and bucco-lingual bone width as stated in earlier studies.[20]

\section{CONCLUSIONS}

DVT plays a promising role in assessment of the amount of bone, the proximity of implant site to vital surrounding structures and anatomical variations at implant sites. Thus, DVT guides in deciding the correct management protocol for successful implant placement with excellent prognosis.

\section{REFERENCES}

[1] Branemark PI, Adell R, Breine U, et al. Intra-osseous anchorage of dental prostheses. I. Experimental studies. Scandinavian Journal of Plastic and Reconstructive Surgery 1969;3(2):81-100.

[2] Ring ME. A thousand years of dental implants: a definitive history -- Part 1. Compendium Contin Educ Dent 1995;16(10):1060-9.

[3] Mupparapu M, Singer SR. Implant imaging for the dentist. J Can Dent Assoc 2004;70(1):32.

[4] Dangore-Khasbage S, Bhowate R. Utility of the morphometry of the maxillary sinuses for gender determination by using computed tomography. Dental and Medical Problems 2018;55(4):411-7.

[5] Karia H, Shrivastav S, Karia AK. Three-dimensional evaluation of the airway spaces in patients with and without cleft lip and palate: a digital volume 
tomographic study. American Journal of Orthodontics and Dentofacial Orthopedics 2017;152(3):371-81.

[6] Kandukuri R, Phatak S. Evaluation of sinonasal diseases by computed tomography. Journal of Clinical and Diagnostic Research 2016;10(11):TC09-TC12.

[7] Choudhary AB, Chaudhary MB, Motwani MB, et al. Utility of cone beam CT in Maxillo-Facial Radiology. Int J Dent Case Reports 2013;3.

[8] Ebrahim F, Iaboni D, Kwon T, et al. Cone Beam CT for preoperative dental implant site assessment: an evidence-based review of the literature. University of Toronto, Faculty of Dentistry 2009.

[9] Chanavaz M, Donazzan. Maxillo-mandibular bone reconstruction and implantology bone and biomaterials. French classification of available bone for implantology. Paris: The book of 30th Congress of Stomatology and Maxillofacial Surgery 1986: p. 189-204.

[10] Chehroudi B, Gould TR, Brunette DM. The role of connective tissue ininhibiting epithelial downgrowth on titanium-coated percutaneous implants. Journal of Biomedical Materials Research 1992;26(4):493-515.

[11] Kircos LT, Misch CE. Diagnostic imaging and technique. Contemporary implant dentistry. $2^{\text {nd }}$ edn. St. Louis, Missouri: Mosby 1999: p. 25-87.

[12] Jaju PP, Suvarna PV, Subramaniam AV, et al. Preevaluation of implant sites by Dentascans. Journal of Dental Implant 2011;1(2):64-74.

[13] De Oliveira RCG, Leles CR, Lindh C, et al. Bone tissue microarchitectural characteristics at dental implant sites.
Part 1: Identification of clinical-related parameters. Clin Oral Impl Res 2012;23(8):981-6.

[14] Shilpa BS, Vasudevan SD, Bhongade ML, et al. Evaluation of survival of $8 \mathrm{~mm}$-length implants in posterior resorbed ridges: a pilot study. J Indian Soc Periodontol 2018;22(4):334-9.

[15] Rothman SL, Chaftez N, Rhodes ML, et al. CT in the preoperative of the mandible and maxilla for endosseous implant surgery. Work in progress. Radiology 1988;168(1):171-5.

[16] Schwarz MS, Rothman SL, Rhodes ML, et al. Computed Tomography: Part I. Preoperative assessment of the mandible for endosseous implant surgery. Int J Oral Maxillofac Implants 1987;2(3):137-41.

[17] Lindhe J, Berglundh T. The interface between the mucosa and the implant. Periodontology 2000 1998;17(1):47-54.

[18] Chakraborty R, Panchbhai A, Bhowate RR, et al. Comparison between conventional radiography and $\mathrm{AD}$ volumetric imaging for location of mandibular canal: in vivo study. J Indian Aca Oral Med Radiol 2017;29(4):26772.

[19] Economopoulos TL, Asvestas PA, Matsopoulos GK, et al. Volumetric difference evaluation of registered threedimensional pre-operative and post-operative CT dental data. Dentomaxillofacial Radiology 2012;41(4):328-39.

[20] Bhattad MS, Baliga S, Vibhute P. A digital volumetric tomography (DVT) study in the mandibular molar region for miniscrew placement during mixed dentition. Dental Press J Orthod 2015;20(2):55-60. 